\title{
The Influence of Birth Country on Selection of Conference Destination - Employing Natural Language Processing
}

\author{
Nitza Davidovitch ${ }^{1} \&$ Eyal Eckhaus ${ }^{1}$ \\ ${ }^{1}$ Ariel University, Ariel, Israel \\ Correspondence: Nitza Davidovitch, Ariel University, Ariel, Israel. E-mail: d.nitza@ariel.ac.il
}

Received: April 12, 2018

Accepted: April 28, $2018 \quad$ Online Published: May 16, 2018

doi:10.5539/hes.v8n2p92

URL: https://doi.org/10.5539/hes.v8n2p92

\begin{abstract}
This study deals with immigrant scientists integrated in academia in Israel. Studies on the subject indicate the contribution of immigrant scientists to research. The current study focuses on the influence of scientists' birth country on selecting destinations for academic conferences, as well as on the influence of one's native language on the academic output resulting from research conferences. This is a pilot study exploring the effect of academic conferences from the perspective of birth country - comparing Israeli born and USSR born academics on the motivation of faculty members to attend conferences, the nature of the conferences they select, the differences between Israeli natives and non-natives with regard to how their perceive the influence of conferences and their contribution to their academic work. This research offers a case study, investigating the effect of scholars from two different countries and cultural background, Israel and USSR. This pioneering research provides the grounds for many extensions, studies that will investigate the impact of other countries and their effect on conference selection.

The study addresses a case study of a single university in Israel that absorbed many immigrant scientists from the former USSR in the 1990s. Ninety-four academic faculty members from various departments answered the questionnaire, of them $60.9 \%$ women and $39.1 \%$ men. Faculty members referred to the conference's contribution with regard to their professional development. In addition, the greater inclination of Israeli researchers than researchers born in the USSR to take their family members with them when travelling for conferences was noted.

Since the contribution of immigrant scientists was found to be significant and since academic conferences are a significant part of the work of faculty members and receive considerable funds from academic institutions, the research findings might illuminate the choice of conferences by immigrant scientists and their preferences compared to native born scientists - with the purpose of examining whether conferences are perceived by Israeli born faculty members as productive.
\end{abstract}

Keywords: academic conference, conference selection, birth country, culture, natural language processing

\section{Introduction}

\subsection{Immigration to Israel}

The effect of countries and their cultural aspects have been discussed extensively in the literature, from which Hofstede's framework (Hofstede, 2011; Hofstede \& Bond, 1984) is the most popular (Moon \& Choi, 2001), and was also used to show that cultural dimentions may affect teching an learning (Hofstede, 1986).

The academia allocates a great deal of resources to the development of conference activities, having a strong belief in the importance of conferences and its contribution to international cooperation among scholars. Accordingly, conference organizers invest enormous resources in the preparation, organization, and the marketing of conferences all over the globe. However, the research on conference selection is underinvestigated, and no study has yet investigated the effect of birth country on conference selection. The purpose of the study is to underline the importance of birth country in the decision process of academic conference selection. This study will offer a significant contribution to the success of conferences, suggesting that conference organizers should take into consideration the birth country when preparing the marketing and communication messages for inviting scholars.

The State of Israel was built on a unique ethno-national basis, seeking to establish its existence on external 
waves of immigration that constitute the demographic foundations of Jewish life in Israel. When the state was founded the Jewish population numbered approximately 650 thousand. Today, seven decades later, the Jewish population encompasses 8 million people, with some $40 \%$ of the growth in this population over the years originating from immigration (CBS, 2007). Israel, as a country of immigrants, coped with large rates of immigration from the moment of its establishment, as well as with challenges involving the absorption of immigrants (Law of Return, 1950).

In previous studies, we focused on the absorption of these immigrant scientists (Davidovitch, Sinuany-Stern, \& Soen, 2010a, b) and their contribution to an academic institution. The story of the immigration and absorption of USSR-born scientists in academia in the 1990s (1989-2009) is a true success story. The previous study (Davidovitch, Sinuany-Stern, \& Soen, 2010ab) was conducted on the $20^{\text {th }}$ anniversary of the immigration of some one million immigrants who came to Israel from the Commonwealth of Independent States (CIS, the former USSR) after the fall of the Iron Curtain, including immigrant scientists absorbed in Israeli academia. The study examined to what degree immigrant scientists were absorbed in Israeli academia in general, over the past 20 years, and by various characteristics, and the achievements of immigrant faculty members in a case study of a single academic institution: Ariel University. At this institution, the considerable contribution of the immigrant scientists is particularly conspicuous, as the institution, which was established with this beginning of this wave of immigration and experienced a dearth of senior academic faculty, gave immigrant scientists the opportunity to join its ranks as regular faculty members. Therefore, this institution is a benchmark for the potential of this group of immigrants, which was not realized in the older and more crowded universities. Their absorption in and contribution to Ariel University are examined in comparison to those of native born faculty members and researchers at Ariel and those who had been in Israel for longer.

Analysis of the data also showed that immigrant scientists from the CIS are conspicuous in academia not only from the perspective of their relative weight, rather their actual scientific contribution is also extremely high. Their weight among outstanding faculty members is considerably higher than their relative weight in the faculty. This is also true of their prominent research scores. The study showed that not only is their contribution higher than that of the other groups - they are also at the top of the pyramid with the highest number of points for studies published in the most prestigious journals.

It has been found that cultures differ in teaching and learning (Hofstede, 1986). The current study, which is the first to examine the output resulting from academic conferences, focused on the effect of academic conferences from the perspective of country of birth -comparing between native born and USSR-born scholars: the motivation of faculty to attend conferences, the nature of the conferences they choose, the differences between native-born and non-native born scholars in their perception of the impact of conferences and their contribution to their academic work.

Academic conferences provide opportunities to expand academic and play vital role in collaboration and communication for the process of scientific knowledge growth (Tang \& Zhang, 2007). Therefore, attending a conference implies taking part in this process of knowledge generation in accordance to the conference themes.

The following are the research hypotheses, as formulated below in the results chapter.

H1. Researchers born in Israel are more oriented to seeking cooperation, than those born in the USSR.

H2. Researchers born in the USSR select conferences based on the theme and topics more than those born in Israel.

H3. Researches who focus on cooperation are more inclined to select conferences in the US.

H4. Researches who focus on conferences based on the theme and topics tend NOT to select conferences in Europe

H5. Researchers born in Israel are more inclined to include family members in their travels to conferences, than those born in the USSR.

\section{Methodology}

\subsection{Initial Sample}

A questionnaire was used for data collection, with six open-ended questions regarding the respondent's opinion on conferences: how they are selected, does the conference size matter, the importance of the forum and the opportunity to meet other researchers, is the publication of proceedings important, and what are the benefits. The responses for each respondent were combined in one text for analysis. Also included were demographic questions regarding place of birth, marital status, and age. A final question asked to which country the 
respondent prefers to travel for conferences. Ninety-six completed questionnaires were collected. The questionnaires were distributed online using Google Docs to the senior faculty members of a single university. Respondents were from 17 different departments, where the minimum was only one respondent from some departments, to a maximum of 14. Sixty-one of the respondents were born in Israel, 16 were born in the USSR, and the rest were born in other countries. For the purpose of this study, only the respondents born in the two dominant places - Israel and the USSR - were selected by the researchers. Regarding gender, $59.2 \%$ of the respondents were females and 40.8\% males. Respondents' age ranged from 34-39 (5.7\%), 40-49 (31.4\%), and $50-80(62.9 \%)$. Regarding marital status $3.9 \%$ of the respondents were single, $85.5 \%$ married, $9.2 \%$ divorced, and $1.3 \%$ widows.

\subsection{Analysis}

R v.3.3.3 For Structural Equation Modeling (SEM) (Asparouhov, Hamaker, \& Muthén, 2017; Fox, 2006) was used to test the model's goodness-of-fit, and SPSS v.25 was used for other statistical procedures, such as correlations. Model fit was estimated using CFI, TLI, RMSEA, and SRMR (McCoach, Gable, \& Madura, 2013). $\chi 2 / d f$ ratio (Hoe, 2008) was included. $>0.95$ cutoff values indicate acceptable fit for CFI and TLI, values $<.06$ for RMSEA, and values $<0.8$ for SRMR (Hu \& Bentler, 1999). $\chi 2 /$ df ratio should be $<3$ (Akbar \& Parvez, 2009).

\subsection{Text Analysis}

First, all the respondents' answers were manually reviewed, showing that most respondents mentioned seeking research cooperation (COOPERATION) as a primary motive in selecting a conference, as well as the conference theme and topics (TOPICS). Next, automated content analysis approaches were used, as follows.

The researchers employed TEXTIMUS, a text mining and analysis software (Eckhaus \& Ben-Hador, 2017). First, $\mathrm{n}$-gram frequencies were generated. $\mathrm{N}$-gram refers to a contiguous sequence of $\mathrm{n}$ words from a given sequence of text. N-gram is often used in Natural Language Processing (NLP) due to its simplicity and relative efficiency (Kovacevic \& Graovac, 2015).

We made use of the Bag-of-Words (BoW) technique. One of the primary branches of traditional text classification is feature selection (Xiao et al., 2017), in which the most popular feature used is BoW (ibid). BoW is known as the most common method of text analysis based on NLP (Razavi, Matwin, De Koninck, \& Amini, 2014). According to BoW, documents are represented as a collection of words, regardless of grammar and order. A set of keywords is explored in all documents and assigned values according to whether the word appears in a document or the frequency at which it appears. Therefore, the researchers analyzed the frequency of all the words, and grouped words with the highest frequency employed for the research variables. Similar to studies that employed BOW (e.g. Eckhaus (2017)), the frequencies of each group were summed to form the variables of COOPERATION and TOPICS. Finally, the dichotomous variable COUNTRY was coded as $0=$ born in Israel, and $1=$ born in the USSR. USA and Europe were also coded dichotomous variables, $1=$ seeks conferences in the region, $0=$ does not seek conference in the region. FAMILY was coded as $0=$ does not include family members on conference trips, and $1=$ includes family members.

\section{Results}

The correlations, means, and standard deviation values between the research variables are presented in Table 1.

Table 1. Spearman correlation matrix, means, and SD

\begin{tabular}{lllllll}
\hline & COOPERATION & TOPICS & COUNTRY & USA & EUROPE & FAMILY \\
\hline COOPERATION & - & & & & & \\
TOPICS & -.18 & - & & & & \\
COUNTRY & $-.32^{* *}$ & $.28^{*}$ & - & & & \\
USA & $.25^{*}$ & -.15 & -.18 & - & & \\
EUROPE & .07 & $-.24^{*}$ & -.11 & $.25^{*}$ & - & \\
FAMILY & .15 & -.11 & $-.31^{* *}$ & -.12 & .04 & - \\
$\quad$ Mean & 1.82 & .09 & .21 & .20 & .36 & .45 \\
$\quad$ SD & 1.52 & .29 & .41 & .40 & .48 & .50 \\
$* p<.05$ & & & & & & \\
$* * p_{p<.01}$ & & & & & &
\end{tabular}

Before constructing the model, the researchers first examined whether the department had an effect on COOPERATION and TOPICS. Two one-way Anova tests were constructed, where COOPERATION and TOPICS 
were the dependent variables in each of the tests respectively, and DEPARTMENT was the independent variable. Results showed no statistical significance for neither of the two tests $(p>.05)$.

Figure 1 illustrates the model and results. The hypothesized model showed a very good fit: $\chi 2 / d f=0.59(p>.05)$, $\mathrm{CFI}=1, \mathrm{TLI}=1.21, \mathrm{RMSEA}=0, \mathrm{SRMR}=0.05 .90 \%$ confidence interval $(\mathrm{CI})$ for RMSEA $(0.12)$. All hypotheses were supported. Researchers born in Israel are more oriented to seeking cooperation than those born in the USSR (H1), researchers born in the USSR select conferences based on the theme and topics more than those born in Israel (H2), scholars who focus on cooperation are more inclined to select conferences in the US (H3), researchers who focus on conferences based on the theme and topics tend to not select conferences in Europe (H4), and researchers born in Israel are more inclined to include family members in their travels to conferences than those born in the USSR (H5).

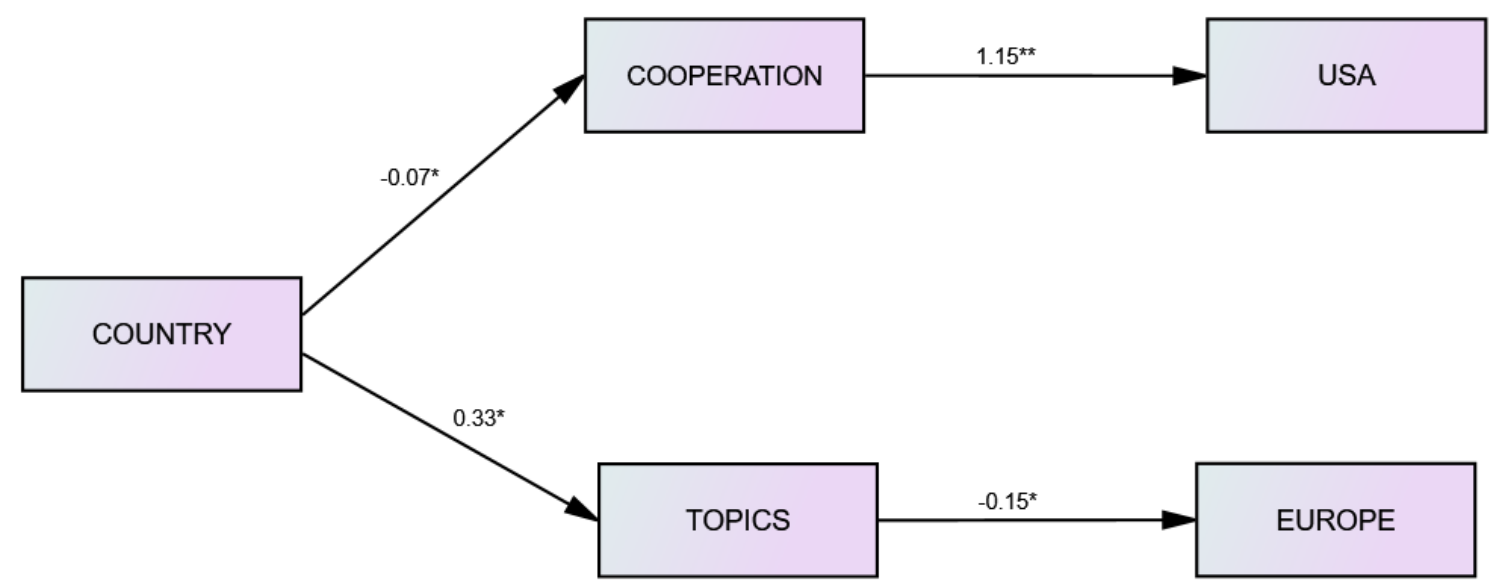

Figure 1. SEM and coefficients

$* p<.05 . ; * * p<.01$.

\section{Summary and Discussion}

This study focuses on immigrant scientists employed in Israeli academia, who conduct research and present their studies at international conferences. The study focused on the effect of scientists' country of birth on choosing the destination of academic conferences, while examining the effect of native language on academic output resulting from research conferences. The research findings show that both native-born and non-native born scholars perceive academic conferences as having a considerable contribution to their professional development. Furthermore, Israeli researchers were found to be more inclined to take their family members with them to conferences than USSR-born researchers. Native-born researchers may see conferences as an opportunity to spend time with their family, while those born in the CIS see conferences as purely work oriented.

Since the contribution of immigrant scientists was found to be significant and since academic conferences are a significant part of the work of faculty members and academic institutions devote significant funds to them, the research findings may illuminate the choice of conferences by immigrant scientists and their preferences compared to native-born scientists, with the purpose of examining whether conferences have a productive effect on their academic work.

Academic conferences often offer complementing activities, such as trips in the conference local area. Researchers who travel with their family may use these opportunities as part of family vacations. The results of this study therefore imply that conference organizers may better target their audience, according to the activities they offer, and attract scholars that will further support the development of new knowledge.

This research offers a case study, investigating the effect of scholars from two different countries and cultural background, Israel and USSR. This pioneering research provides the grounds for many extensions, studies that will investigate the impact of other countries and their effect on conference selection.

\section{References}

Akbar, M. M., \& Parvez, N. (2009). Impact of service quality, trust, and customer satisfaction on customers loyalty. ABAC Journal, 29(1), 24-38.

Asparouhov, T., Hamaker, E. L., \& Muthén, B. (2017). Dynamic structural equation models. Structural Equation 
Modeling: A Multidisciplinary Journal, 1-30.

Eckhaus, E. (2017). A shift in leadership. Academy of Strategic Management Journal, 16(1), 19-31.

Davidovitch, N., Sinuany-Stern, Z., \& Soen. D. (2010a). Cultural capital and the riches of manna: integration of immigrant scientists in Israel academia. Problems of Education in the $2 I^{\text {st }}$.Century, 20(20), 118-134.

Davidovitch, N., Soen, D., \& Sinuany-Stern, Z. (2010b). Were Russian immigrant scientists absorbed in Israeli academia? The test case of one academic institution attests to a positive trend. Kivunim Hadashim Journal for Zionism, Judaism, Policy, Society and Culture, 23, 188-199. (In Hebrew).

Eckhaus, E., \& Ben-Hador, B. (2017). Gossip and gender differences: a content analysis approach. Journal of Gender Studies, Published online at: http://www.tandfonline.com/doi/full/10.1080/09589236.2017.1411789, 1-12. https://doi.org/10.1080/09589236.2017.1411789

Fox, J. (2006). Teacher's corner: structural equation modeling with the sem package in R. Structural Equation Modeling, 13(3), 465-486. https://doi.org/10.1207/s15328007sem1303_7

Hoe, S. L. (2008). Issues and procedures in adopting structural equation modeling technique. Journal of Applied Quantitative Methods, 3(1), 76-83.

Hofstede, G. (1986). Cultural differences in teaching and learning. International Journal of Intercultural Relations, 10(3), 301-320. https://doi.org/10.1016/0147-1767(86)90015-5

Hofstede, G. (2011). Dimensionalizing cultures: The Hofstede model in context. Online readings in psychology and culture, 2(1), 1-26. https://doi.org/10.9707/2307-0919.1014

Hofstede, G., \& Bond, M. H. (1984). Hofstede's culture dimensions: An independent validation using Rokeach's value survey. Journal of Cross-Cultural Psychology, 15(4), 417-433. https://doi.org/10.1177/0022002184015004003

Hu, L. T., \& Bentler, P. M. (1999). Cutoff criteria for fit indexes in covariance structure analysis: Conventional criteria versus new alternatives. Structural Equation Modeling: A Multidisciplinary Journal, 6(1), 1-55. https://doi.org/10.1080/10705519909540118

Kovacevic, J., \& Graovac, J. (2015). Application of a structural support vector machine method to n-gram based text classification in Serbian. Infotheca-Journal for Digital Humanities, 16(1-2), 5-23. https://doi.org/10.18485/infotheca.2016.16.1_2.1

McCoach, D. B., Gable, R. K., \& Madura, J. P. (2013). Evidence based on the internal structure of the instrument: factor analysis. Instrument Development in the Affective Domain, 109-161. https://doi.org/10.1007/978-1-4614-7135-6_4

Moon, H.-C., \& Choi, E.-K. (2001). Cultural impact on national competitiveness. Journal of International and Area Studies, 21-36.

Razavi, A. H., Matwin, S., De Koninck, J., \& Amini, R. R. (2014). Dream sentiment analysis using second order soft co-occurrences (SOSCO) and time course representations. Journal of Intelligent Information Systems, 42(3), 393-413.

Tang, X., \& Zhang, Z. (2007). How knowledge science is studied-a vision from conference mining of the relevant knowledge science symposia. International Journal of Knowledge and Systems Sciences, 4(4), 51-60.

Xiao, G., Mo, J., Chow, E., Chen, H., Guo, J., \& Gong, Z. (2017). Multi-Task CNN for classification of Chinese legal questions. Paper presented at the e-Business Engineering (ICEBE), 2017 IEEE 14th International Conference. https://doi.org/10.1109/ICEBE.2017.22

\section{Copyrights}

Copyright for this article is retained by the author(s), with first publication rights granted to the journal.

This is an open-access article distributed under the terms and conditions of the Creative Commons Attribution license (http://creativecommons.org/licenses/by/4.0/). 